\title{
Interactive comment on "Nonlinear forcing mechanisms of the terdiurnal solar tide and their impact on the zonal mean circulation" by Friederike Lilienthal and Christoph Jacobi
}

\section{Anonymous Referee \#1}

Received and published: 14 June 2019

This paper investigates the forcing mechanisms of the terdiurnal solar tide in the middle atmosphere using a mechanistic global circulation model. Three are identified: Solar heating which is the most prominent, wave-wave interaction (between diurnal and semidiurnal tides) and tide-gravity wave interaction that are secondary. The authors also test the sensitivity of the background winds and temperatures to enhancements of the different sources. Incremental gravity wave drag is found to generate the strongest terdiurnal amplitude responses, and changes to the background winds.

The paper can be published, with the following revisions: The material reported in sections 1, 2, and 3.1 reprises findings reported in Lilienthal et al., 2018, and I saw 
little value in it. I recommend that section 3.1 be cut, or very briefly summarized. The paper should only report the new information appearing in section 3.2 and beyond, and ANGEOD Figures 3 and onward.

I also recommend that it be edited for proper English grammar and usage.

Minor comments:

1. The text refers to panels $a$ and $b$ in Figure 4, but these labels that do not appear in the plots. Please recheck all Figures for this issue.

Interactive comment on Ann. Geophys. Discuss., https://doi.org/10.5194/angeo-2019-37, 2019. 